Research Article

\title{
A Study on Mode Shape and Natural Frequency of Rotating Flexible Cracked Annular Thin Disk
}

\author{
Jinghe Zhao $\mathbb{D}$, Ying Zhang, and Bo Jiang \\ School of Mechanical Engineering, Changchun Guanghua University, Changchun 130033, China \\ Correspondence should be addressed to Jinghe Zhao; zhaojinghe-1982@163.com
}

Received 7 June 2021; Revised 9 August 2021; Accepted 7 September 2021; Published 18 September 2021

Academic Editor: Hassan Haddadpour

Copyright ( 2021 Jinghe Zhao et al. This is an open access article distributed under the Creative Commons Attribution License, which permits unrestricted use, distribution, and reproduction in any medium, provided the original work is properly cited.

\begin{abstract}
As an important rotating component, the flexible annular thin disk is widely used in mechanical engineering. Cracks may occur in some weak disk parts, which will greatly shorten the equipment service life and even cause equipment failure. Due to the centrosymmetric structure of the flexible annular disk, two typical cracks are studied in this paper; one is radial crack parallel to diameter, including radial closed crack (RC-crack) and radial opening crack (RO-crack); the other one is vertical crack perpendicular to diameter, including circumferential crack (CF-crack) and tangential crack (TG-crack). The effect of crack parameters, such as crack length, direction, and position, on disk vibration characteristics are studied through theoretical simulation and experimental verification. The research shows that the effect of cracks on vibration characteristic gets more obvious with cracks extending in most cases, RO-crack decreases the natural frequency obviously, and vertical cracks would affect mode shapes. In addition, the bigger the nodal diameter is, the more obvious the effect gets. Meanwhile, the most obvious effect appears in the mode of a nodal diameter locating on the crack. The research possesses some guiding significance in industrial production; by comparing with the vibration characteristics of the flawless disk, the integrity of the rotating flexible disk can be judged to prevent possible equipment damage.
\end{abstract}

\section{Introduction}

As one of the most important structures of mechanical equipment, the flexible disk is widely used in mechanical engineering, such as circular saw blades, disc brake, steam turbine, and hard disk driver. The equipment performance depends on the rotating flexible disk status to a certain extent. There is a great significance to research the vibration characteristic of rotating flexible disk. Lamb and Southwell [1] derived the dynamic model of the high-speed rotating flexible disk and calculated its vibration modes and natural frequencies, and Chung et al. [2] studied the natural frequencies of rotating disks in fixed and rotating coordinates. Kwak and Amabili [3] and Amabili and Dalpiaz [4] carried out some experimental works on the vibrations of annular disk plates. The calculation method of disk natural frequencies was presented in Amabili and Garziera [5] under different boundary conditions.

Cracks exist in the various mechanical equipment widely; the research on the mechanical structure with cracks has been attracting the attention of scientists for a long time. Krawczuk [6, 7] established a rectangular plate finite element with a through crack based on elastoplastic fracture mechanics and the finite element method. Ismail and Cartmell [8] researched the vibration of the plate with a surface crack of variable angular orientation based on classical plate theory. Lin and $\mathrm{Ng}$ [9] researched the effect of breathing cracks on vibration characteristics of the beam and proved the effectiveness of higher mode frequency response functions to the detection and damage assessment.

Cracks may occur in some weak parts due to plastic deformation, product defect, and centrifugal force, which will greatly shorten the equipment service life and even cause equipment failure. In order to avoid the equipment damage caused by cracks, it is valuable to build up a crack detection method to find the crack as quickly as possible. The nondestructive testing method plays an important role in the crack fault diagnosis of rotating machinery, which can detect the cracks in the mechanical structure without damaging the 
product integrity, surface texture, and future usability. Carden and Faning [10] proposed a function of vibration signal analysis in judging crack types. Pennachi et al. [11] developed a transverse crack identification program, which can detect crack depth and location by analyzing the vibration components of the rotor dynamic response. Bennoud et al. [12] proposed a nondestructive testing method based on eddy currents to detect cracks. Chen [13] analyzed a tilted cracked rotor system with two disks by finite element model and simulated the time-varying stiffness caused by axial cracks. Cavalini et al. [14] proposed a method of crack detection and recognition based on nonlinear technology, which can distinguish the dynamic behavior of breathing and opening crack models.

As an important high-speed rotating structure, the integrity of rotating flexible disk determines the performance of mechanical equipment, and the research of flexible cracked disk has attracted a larger number of scholars for a long time. Anifantis et al. [15] proposed a crack identification method of annular plates firstly according to the phenomenon that the natural frequency of the plate decreases due to the presence of the crack. Chung and Kim [16] identified a fracture mechanism of a spinning optical disk and proposed a method of preventing the disk fracture which is reinforcing the clamping area by structural modifications.

The natural frequency is one of the typical vibration characteristics, which can reflect the performance of disk structure to a certain extent. In the researched works of radial cracked disk, Mirsalimov and Kalantarly [17] built up a disk model with a bridged crack and obtained closed algebraic system of equations and limit condition of the crack growth through numerical calculation. Meanwhile, on the research of circumferential cracked disk, Pramod et al. [18] investigated the natural frequencies of annular plates with circumferential cracks by finite element method. Derakhshan et al. [19] researched the effect of crack radial location and its depth on the natural frequencies and mode shapes of an annular plate with a circumferential crack. Bahaloo et al. [20] researched the transverse vibration and stability of rotating annular disk with a circumferential crack and found the phenomenon that the disk critical speed will decrease with the crack depth increasing and the crack radius decreasing. Bose and Mohanty [21] studied the large amplitude axisymmetric vibration of circular disk with circumferential crack and the natural frequency variations of axisymmetric modes through combining the Berger's approximation, Galerkin's method, and multiple scales method. Furthermore, some researchers have systematically studied the vibration characteristics of flexible annular disks; Yuan $[22,23]$ deduced the analytical formula of the natural frequency of flexible cracked disk and gave the natural frequency parameters for the free vibration of annular, circular, and sectorial plates. Demir [24, 25] proposed a method of judging crack position by natural frequency and calculated the natural frequencies of annular plates with circumferential cracks and radial through cracks.

As the foundation of crack detection technology, vibration characteristic analysis of flexible cracked disk is an effective method to realize the accurate detection and discovery of minor damage. In this paper, the effects of cracks with different parameters, including crack types, lengths, directions, and positions, on vibration modes and natural frequencies of rotating flexible disk are investigated by theoretical simulation and experimental test. The research method of theoretical simulation analysis is building up the finite element models of rotating flexible disks, calculating its vibration characteristic, and studying the effect regular of crack lengths, directions, and positions on vibration modes and its corresponding natural frequencies. And then, the effect regular of various cracks is verified on vibration characteristic of the flexible cracked disk by experimental test. In the process of experimental test, the sound and displacement signals are collected and processed preliminary to obtain the time-domain characteristics of rotating flexible cracked disk, and the natural frequencies are calculated and obtained by frequency-domain analysis.

Different from previous works as reviewed above, this paper discussed the general decaying law of mode shape and natural frequency of rotating flexible disk with various types of cracks, and both theoretical finite element simulation and specialized experimental testing are carried out and compared for result verification; then, the results and observations in this paper should be more valuable and practical for the fault detection and diagnosis of rotating disk system.

\section{Model Establishment}

2.1. Physical Property Parameters. In this paper, the physical property parameters of flexible annular thin disk are listed in Table 1.

The flexible disk rotor is clamped and fixed on a rotation shaft by a ring which led disk rotor inner edge to be fixed and outer edge to be free. Therefore, the researched object of vibration characteristics is the deformable part of the rotating flexible annular thin disk, which is from the ring outer edge to the disk outer edge. The ring diameter is set to $32 \mathrm{~mm}$ in this paper. According to the physical property parameters, the theoretical models and experimental models of the flexible cracked annular thin disks are established, respectively, for the subsequent research.

2.2. Crack Classification. Due to the centrosymmetric ring structure of the flexible annular thin disk, two typical cracks are selected according to the position relationship between crack and diameters as a common assumption and simplification in the crack academic research [6-16]. The typical radial and circumferential cracks are selected also in the view of radial and circumferential membrane stresses consistently in the rotating disk. In practices, the radial and circumferential cracks are most often taking place in the rotating thin disk. One is radial crack which is parallel to the diameter, including radial closed crack (RC-crack) inside the disk completely and radial opening crack (RO-crack) opening at disk outer edge; the other one is vertical crack which is perpendicular to the diameter, including circumferential crack (CF-crack) and tangential crack (TG-crack). 
TABLE 1: Physical property parameters of the flexible annular thin disk.

\begin{tabular}{lcccccc}
\hline Material & $R_{o}(\mathrm{~mm})$ & $R_{i}(\mathrm{~mm})$ & $h(\mathrm{~mm})$ & $\rho\left(\mathrm{g} / \mathrm{cm}^{3}\right)$ & $E(\mathrm{GPa})$ & $v$ \\
\hline Galvanized sheet & 47.5 & 12.5 & 0.2 & 7.84 & 200 & 0.3 \\
\hline
\end{tabular}

All kinds of cracks are through cracks, and the maximum width of each crack is set as $50 \mu \mathrm{m}$. The flexible annular thin disk with four kinds of cracks is shown in Figure 1.

2.3. Theoretical Model. Four kinds of flexible cracked annular thin disks are established using ANSYS Workbench, and the crack parameters, such as crack length, direction, and position, are considered in the modeling process. Because the deformation and vibration of the clamped part could be ignored, the finite element model of flexible disk is simplified as a single component with an inner diameter of $32 \mathrm{~mm}$ and a fixed inner edge.

With the software ANSYS Workbench, the SOLID186 element is used to model the annular thin disk. In the view of result convergence, the grid types of coarse (first spacing $0.12 \mathrm{~mm}$ ), medium (first spacing $0.08 \mathrm{~mm}$ ), and fine (First spacing $0.04 \mathrm{~mm}$ ) are calculated, respectively, for convergence analysis, and the their frequency error is less than $1 \%$. For the disk material models and parameters had been provided in Table 1 in detail. At the inner cylindrical edge of annular thin disk, the clamping full constraints in six degrees of freedoms are applied, and others are free boundary without any constraint.

In order to ignore the effect of crack shape and ensure the reliability of simulation data, each crack is designed in three shapes, that is, rectangle, round-rectangle, and diamond (which is triangle for $\mathrm{RO}$-cracks). The data processing method of three-shape cracks is comparing the simulation results of cracked disks with three shapes, eliminating errors, and averaging. The finite element models of the flexible annular thin disk with four kinds of cracks are illustrated in Figure 2(a) and three-shape cracks are shows in Figure 2(b).

2.4. Experimental Model. The effect of short TG-crack is similar to CF-crack due to their similar crack configurations; thus TG-crack and CF-crack are regarded as the same kind of crack in the experimental test. Corresponding with the finite element models, three kinds of cracked disks physical models, namely, RO-crack, RC-crack, and CF-crack, are customized, respectively. The physical model is clamped by a $32 \mathrm{~mm}$ diameter ring and the deformable part is the same as the finite element modal. The disk surface is sprayed black and affixed with reflective sheets so as to accurately measure the disk rotating speed. The physical models of three kinds of cracked disks are shown in Figure 3.

\section{Computation Simulation}

The vibration modes and their corresponding natural frequency could be obtained by analyzing the finite element model of each cracked disk. Except for the modes without nodal diameter, each vibration mode of rotating flexible cracked disk can be divided into two modes comparing with flawless disk: one is the mode where a nodal diameter of vibration mode is just located on the crack; the other one is the mode where no nodal diameter is coincident (or intersects) with the crack. Therefore, in the same research range of natural frequency, the mode with the same nodal diameter of the cracked disk is twice as much as the flawless disk. For the convenience of description, mode A is used to represent the former while mode $B$ represents the latter in this paper. The first five modes of flawless disk and the first nine modes of four kinds of cracked disk are shown in Figure 4 .

There is no nodal circle in the first nine modes of the rotating flexible cracked disk; that is, the number of the nodal circle is zero. According to Figure 4, the vibration modes of the flexible disk with RC-crack, CF-crack, and TGcrack are similar; that is, the first mode stands for mode $(0$, $0)$, the second mode stands for mode $(0,1) B$, the third mode stands for mode $(0,1) \mathrm{A}$, the fourth mode stands for mode $(0$, $2) \mathrm{B}$, the fifth mode stands for mode $(0,2) \mathrm{A}$, the sixth mode stands for mode $(0,3) \mathrm{B}$, the seventh mode stands for the mode $(0,3) \mathrm{A}$, the eighth mode stands for the mode $(0,4) \mathrm{B}$, and the ninth mode stands for the mode $(0,4) \mathrm{A}$. For the flexible annular thin disk with RO-cracks, the mode A and mode $B$ including the same nodal diameter are just on the contrary.

3.1. Characteristic Parameter Setting. Because all kinds of cracks are through cracks, the determinants of crack configuration include crack length, direction, and position.

3.1.1. Crack Length. Because the crack width is set as $50 \mu \mathrm{m}$ in advance, the crack size is mainly determined by crack length. The effects of crack length of RO-crack, RC-crack, CF-crack, and TG-crack on the vibration characteristic of the flexible disk are researched in this paper, and crack length of four kinds of cracks ranges from $1 \mathrm{~mm}$ to $25 \mathrm{~mm}$. In addition, the crack should be located near the middle position of the disk deformable part to avoid the effect of eccentricity, and the crack midpoint radius is set as $31.75 \mathrm{~mm}$. The natural frequencies of the rotating flexible cracked annular thin disk with various lengths are shown in Figure $5\left(\mathrm{a}_{\mathrm{i}}\right)$.

3.1.2. Crack Direction. The intersection angle between crack and disk diameter is a typical characteristic of the crack relative to flexible disk. TG-crack could be considered to be the condition where the intersection angle of $\mathrm{RC}$-crack is 90 degrees, and the CF-crack is concentric with the flexible disk. Therefore, RO-cracks and RCcracks of various intersection angles are studied. The same as the research of crack length, the crack midpoint radius is set as $31.75 \mathrm{~mm}$ to avoid the effect of eccentricity, and 


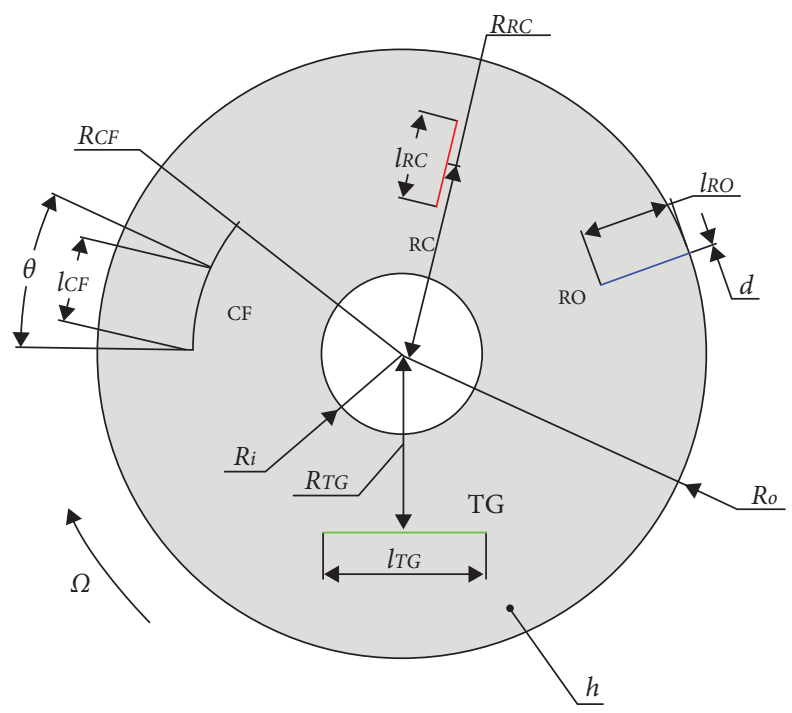

FIGURE 1: Schematic diagram of the flexible cracked annular thin disk with four kinds of cracks: RO: radial opening crack, RC: radial closed crack, CF: circumferential crack, TG: tangential crack.

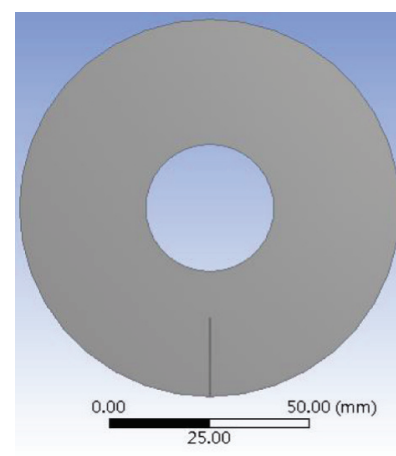

$\left(a_{1}\right)$

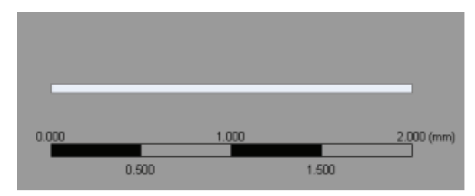

$\left(b_{1}\right)$

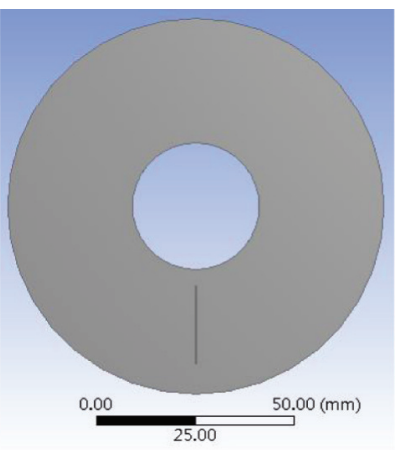

$\left(\mathrm{a}_{2}\right)$

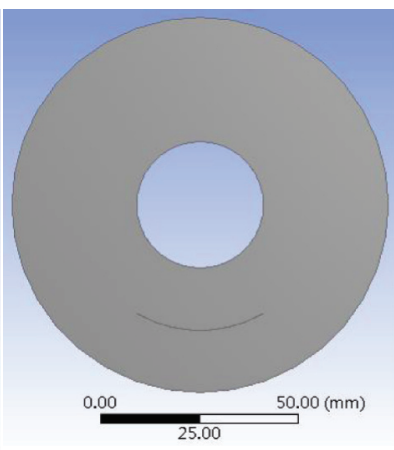

$\left(a_{3}\right)$

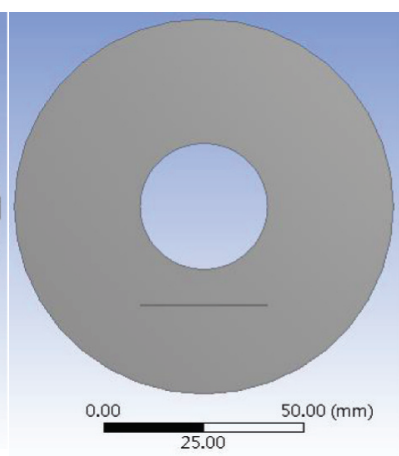

$\left(a_{4}\right)$

(a)

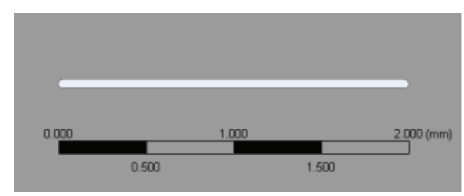

$\left(b_{2}\right)$

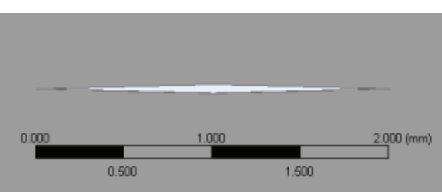

$\left(b_{3}\right)$

(b)

FIGURE 2: Finite element models of flexible cracked annular thin disks $\left(\mathrm{a}_{i}\right)$ four kinds of cracks, $i=1,2,3,4,\left(\mathrm{~b}_{j}\right)$ three shapes of RC-cracks, $j=1,2,3$. $\left(a_{1}\right)$ RO-crack (RO20), $\left(a_{2}\right)$ RC-crack (RC20), $\left(a_{3}\right)$ CF-crack (CF60), $\left(a_{4}\right)$ TG-crack (TG32), (b1) rectangle crack, $\left(b_{2}\right)$ roundrectangle crack, and $\left(b_{3}\right)$ diamond crack.

the crack length is $16 \mathrm{~mm}$. According to comparing the crack direction with the disk rotating direction, the intersection angle could be divided into the negative and positive angle; the range of intersection angle is set as $\pm 80^{\circ}$. Because the effects of negative and positive angles on the vibration characteristic are similar and the error could be ignored, the natural frequency of both is taken as the average and is shown in Figure $5\left(b_{\mathrm{i}}\right)$.
3.1.3. Crack Position. The crack position will affect the stability and integrity of the disk structure, which is mainly stood by the crack midpoint radius in this paper. Due to the special centrosymmetric structure of rotating flexible disk, the effect of the position of RC-crack, CF-crack, and TGcrack on the vibration characteristic of the flexible cracked disk should be considered. RC-crack with a length of $8 \mathrm{~mm}$, CF-crack with a span angle of 40 degrees, and TG-crack with 


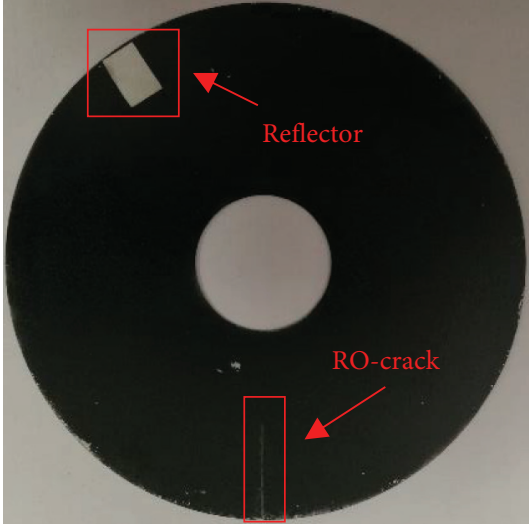

(a)

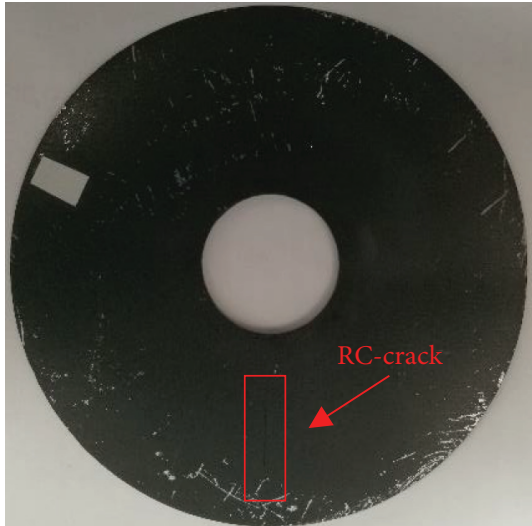

(b)

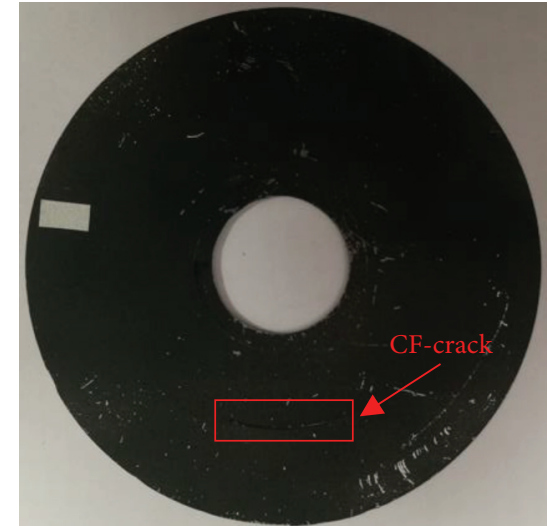

(c)

FIGURE 3: The physical photograph of three kinds of flexible cracked annular thin disks: (a) RO-crack (RO18), (b) RC-crack (RC12), and (c) CF-crack (CF40).

a length of $30 \mathrm{~mm}$ are selected to research the effect of crack position on the natural frequency. And the crack midpoint radius ranges from $21 \mathrm{~mm}$ to $42 \mathrm{~mm}$. The natural frequencies of rotating flexible cracked annular thin disks with various positions are shown in Figure $5\left(c_{i}\right)$.

3.2. Crack Length. It can be seen from Figure $5\left(a_{\mathrm{i}}\right)$ that the effect of RO-crack is the most obvious on the natural frequency; meanwhile, the more the nodal diameters the vibration modes include, the more obvious the effects of crack on the natural frequency will be in most cases. The change trend of natural frequency caused by radial crack and vertical crack is similar though different change ratios. It shows that no matter what kinds of cracks, the change of natural frequency caused by a short crack is negligible, and the natural frequency decreases gradually with cracks extending. For the effect of crack length on natural frequency, on one hand, the effects of opening crack on vibration characteristics are more obvious than closed crack, and the natural frequencies change more obviously when a nodal diameter of vibration modes is just located at the opening crack, while the effect of closed crack is just on the contrary. On the other hand, the effect of radial crack on the vibration characteristic is more serious than the vertical crack of equal length.

The research range of vertical crack length can be expanded, the natural frequencies of the flexible annular thin disk with CF-crack and TG-crack are calculated and shown in Figure $6\left(\mathrm{a}_{i}\right)$.

It can be found from Figure $6\left(a_{i}\right)$ that when the span angle of CF-crack is larger than 60 degrees and the crack length of TG-crack is greater than $35 \mathrm{~mm}$, the natural frequency will decrease sharply, the reason of which is that the mode $(1,0)$ occupied the corresponding position of mode $(0$, $4) \mathrm{B}$, and the obvious effect comes from mode $(1,0)$. The eighth modes of CF-crack and TG-crack are shown in Figure $6\left(b_{i}\right)$. The phenomenon shows that the higher modes tend to occupy lower mode positions, and its shape changes obviously with vertical crack extending, while the change of the first seven modes and their natural frequencies are not obvious in the current research range. And the vertical crack could lead to a more evident effect on the structure of the flexible disk and change the deformation of the flexible cracked annular thin disk.

3.3. Crack Direction. It can be seen from Figure $5\left(b_{i}\right)$ that the effects of RO-cracks are more obvious on the natural frequencies with the intersection angle increasing, while the most modes of RC-crack are negligible, which corresponds to the effect of crack length. The effect trend of two kinds of crack is similar; as the intersection angle of crack increases, the natural frequencies of the first three modes decrease but higher modes are on the contrary. The changing trend of natural frequency led by intersection angle is just opposite to that led by crack length. In order to research the relationship between intersection angle and crack length on the natural frequency, the change ratio of natural frequency between flawless disk and cracked disk with intersection angle of $80^{\circ}$ is listed in Table 2.

The data of Table 2 provides evidence that the effect of crack length on the natural frequency could be counteracted partly with the increase of intersection angle, and the vibration of flexible disk is the most violent when the crack parallels with diameter. The result indicates that when the calculation error is ignored, the effect of RC-crack is larger than TG-crack of equal length to a certain extent, which corresponds with the effect of crack length.

3.4. Crack Position. It can be seen from Figure $5\left(c_{i}\right)$ that as crack midpoint radius increases, the natural frequency of the flexible disk with RC-crack decreases slowly, while CF-crack and TG-crack increase slowly or first decline and then go upward. However, the change is limited in most cases; the change trend of natural frequencies is still relatively gentle even if there is a long crack. Moreover, each vibration mode appears regularly with no change in shape with the crack position changing. It shows that the crack position has a little effect on the overall structure of the rotating flexible cracked annular thin disk. 


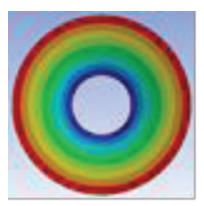

$\left(a_{1}\right)$

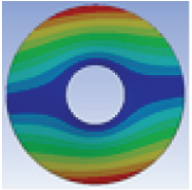

$\left(a_{2}\right)$

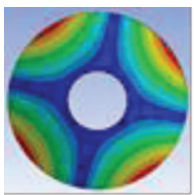

$\left(a_{3}\right)$

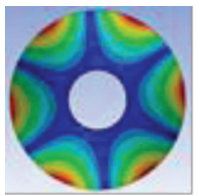

$\left(\mathrm{a}_{4}\right)$

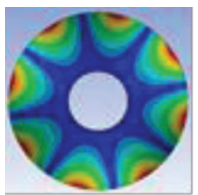

$\left(a_{5}\right)$

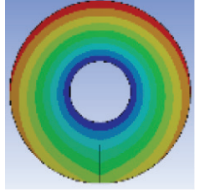

$\left(b_{1}\right)$

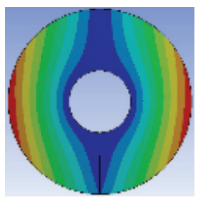

$\left(b_{2}\right)$

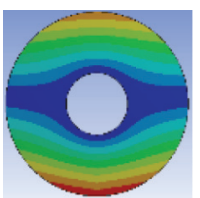

$\left(b_{3}\right)$

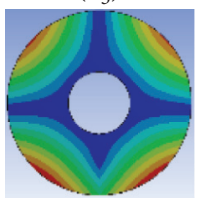

$\left(b_{4}\right)$

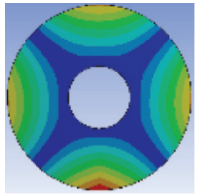

$\left(b_{5}\right)$

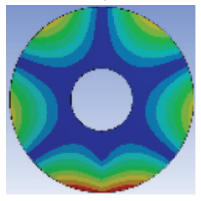

$\left(b_{6}\right)$

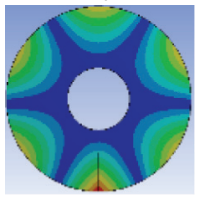

$\left(b_{7}\right)$

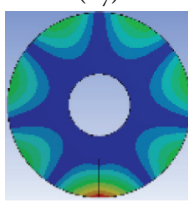

$\left(b_{8}\right)$

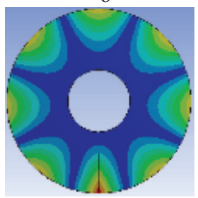

$\left(b_{9}\right)$

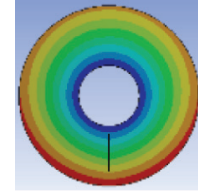

$\left(c_{1}\right)$

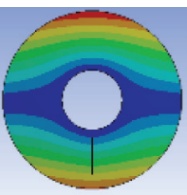

$\left(c_{2}\right)$

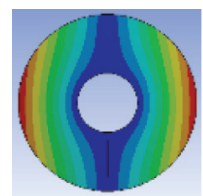

$\left(c_{3}\right)$

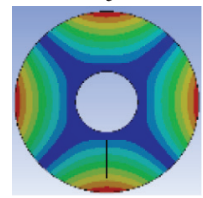

$\left(c_{4}\right)$

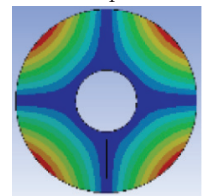

$\left(c_{5}\right)$

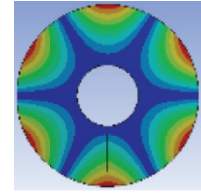

$\left(c_{6}\right)$

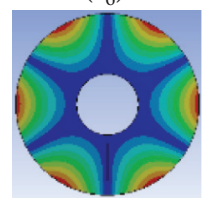

$\left(c_{7}\right)$

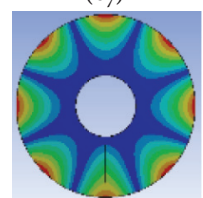

$\left(c_{8}\right)$

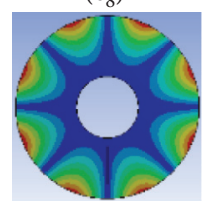

$\left(c_{9}\right)$

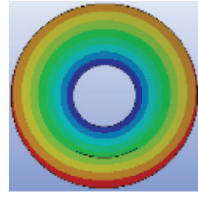

$\left(\mathrm{d}_{1}\right)$

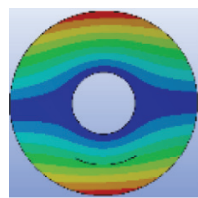

$\left(d_{2}\right)$

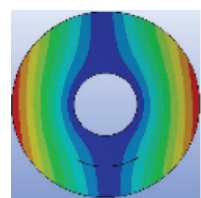

$\left(d_{3}\right)$

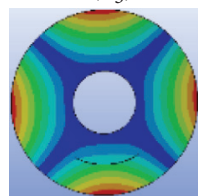

$\left(\mathrm{d}_{4}\right)$

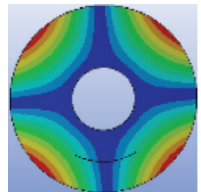

$\left(d_{5}\right)$

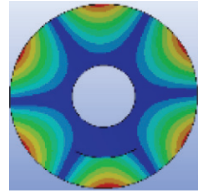

$\left(d_{6}\right)$

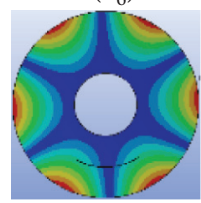

$\left(d_{7}\right)$

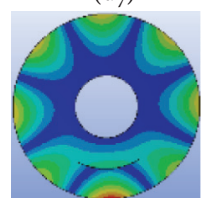

$\left(\mathrm{d}_{8}\right)$

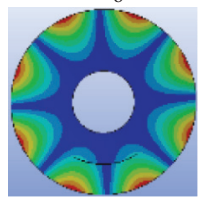

$\left(d_{9}\right)$

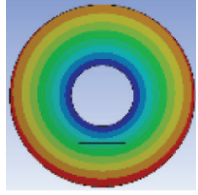

$\left(e_{1}\right)$

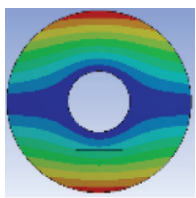

$\left(e_{2}\right)$

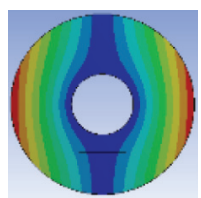

$\left(\mathrm{e}_{3}\right)$

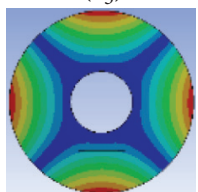

$\left(\mathrm{e}_{4}\right)$

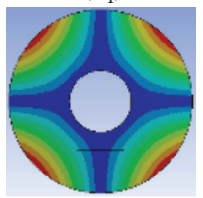

$\left(\mathrm{e}_{5}\right)$

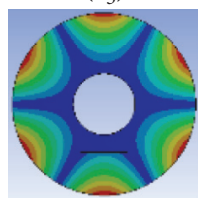

$\left(\mathrm{e}_{6}\right)$

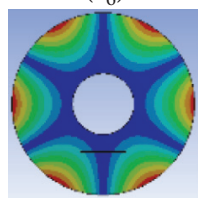

$\left(\mathrm{e}_{7}\right)$

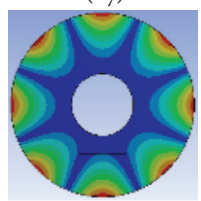

$\left(\mathrm{e}_{8}\right)$

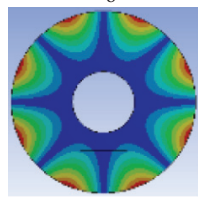

$\left(e_{9}\right)$

FIGURE 4: The vibration modes of rotating flexible annular thin disks with various cracks: $\left(\mathrm{a}_{i}\right)$ flawless flexible disk, $\left(\mathrm{b}_{i}\right)$ flexible disk with ROcrack of $20 \mathrm{~mm}$ (RO20), $\left(\mathrm{c}_{i}\right)$ flexible disk with RC-crack of $20 \mathrm{~mm}$ (RC20), $\left(\mathrm{d}_{i}\right)$ flexible disk with CF-crack of 60 degrees $(\mathrm{CF} 60),\left(\mathrm{e}_{i}\right)$ flexible disk with TG-crack of $32 \mathrm{~mm}$ (TG32), $i$ is each vibration mode's order, and $i=1,2, \ldots, 9$. 


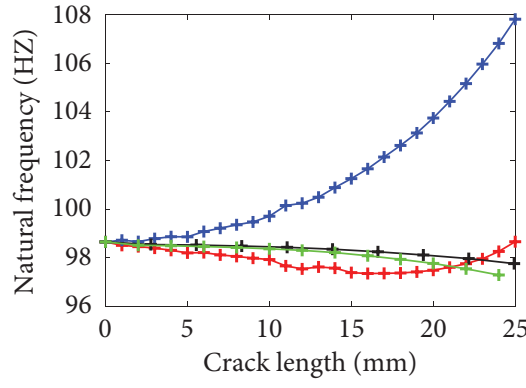

$\left(a_{1}\right)$

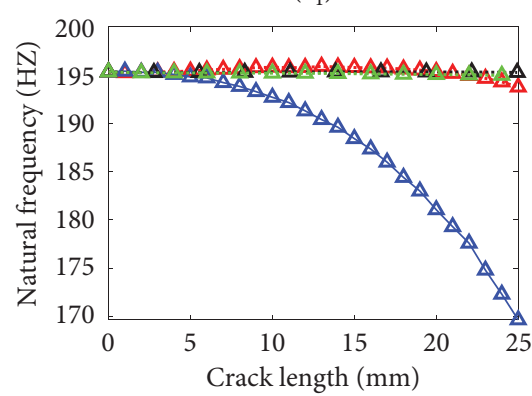

$\left(\mathrm{a}_{4}\right)$

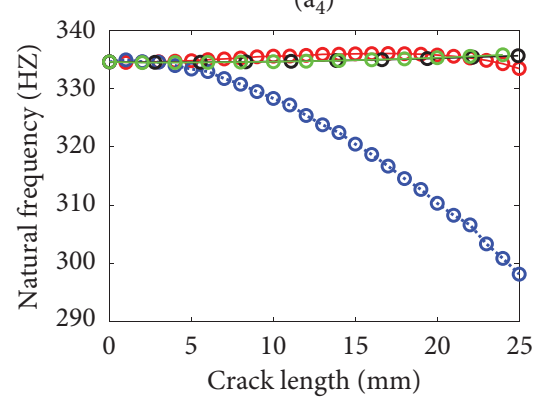

$\left(a_{7}\right)$

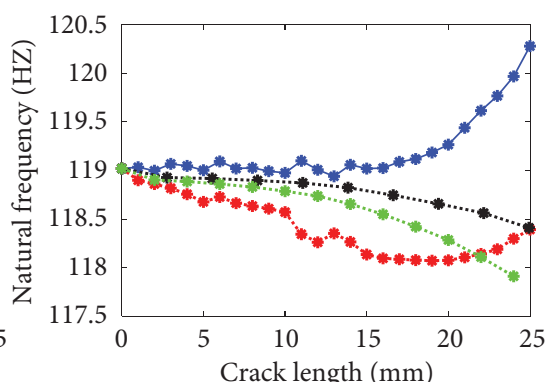

$\left(a_{2}\right)$

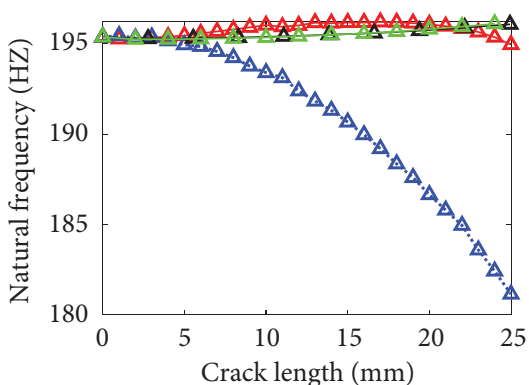

$\left(a_{5}\right)$

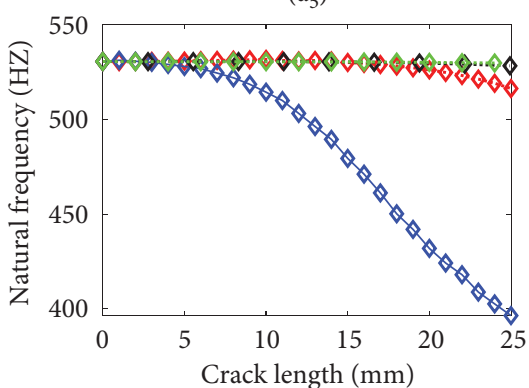

$\left(a_{8}\right)$

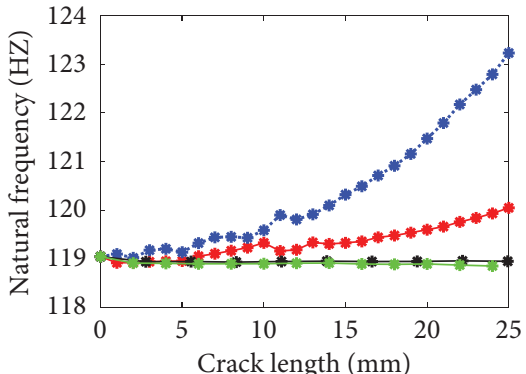

$\left(a_{3}\right)$

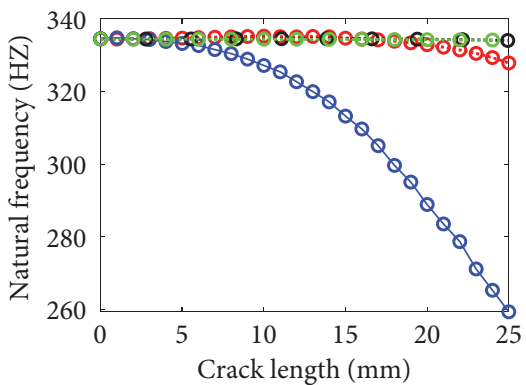

$\left(a_{6}\right)$

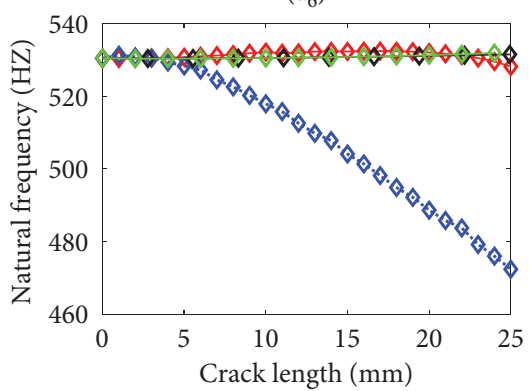

$\left(a_{9}\right)$

(a)

Figure 5: Continued. 


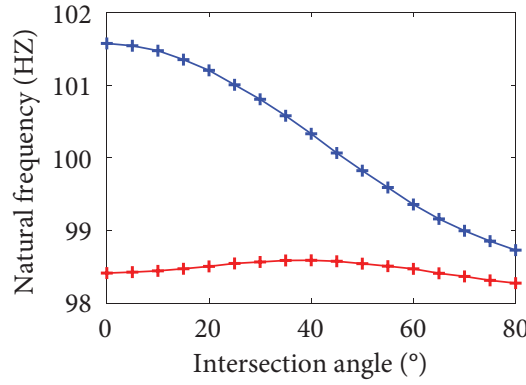

$\left(b_{1}\right)$

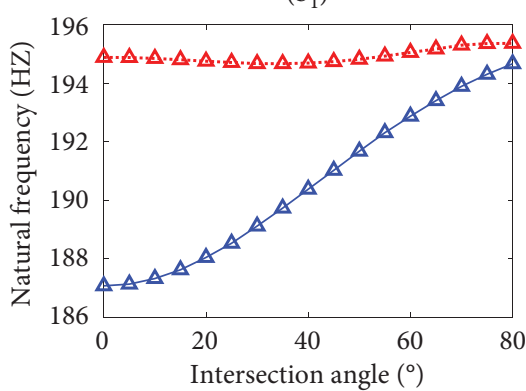

$\left(b_{4}\right)$

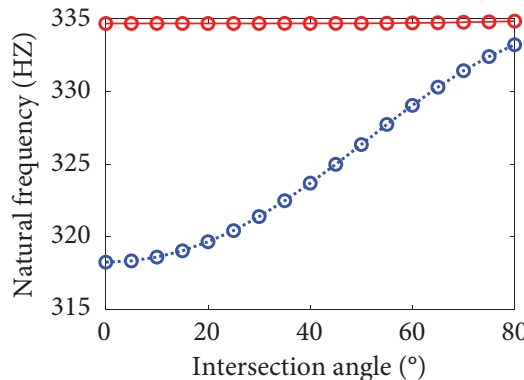

$\left(b_{7}\right)$

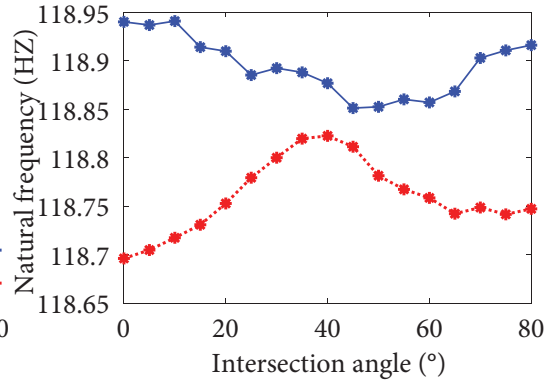

$\left(b_{2}\right)$

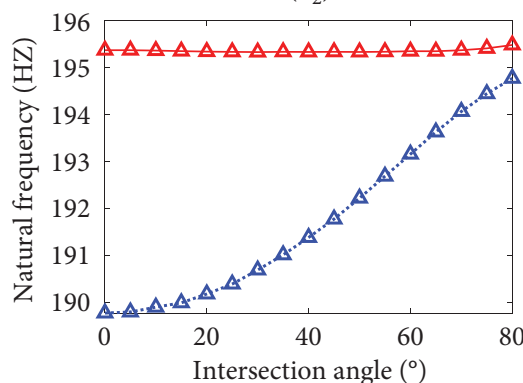

$\left(b_{5}\right)$

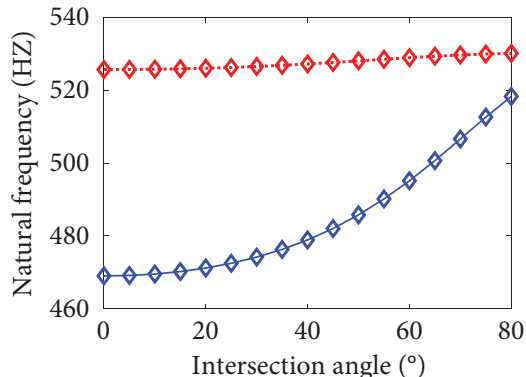

$\left(\mathrm{b}_{8}\right)$

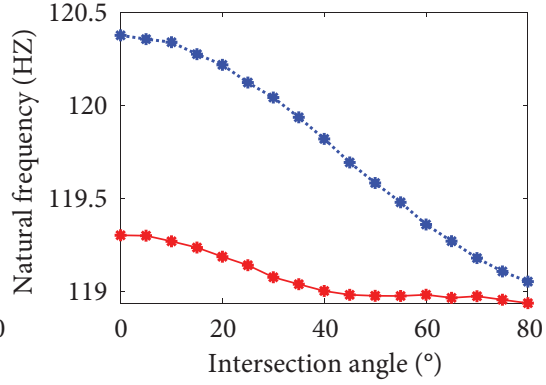

$\left(b_{3}\right)$

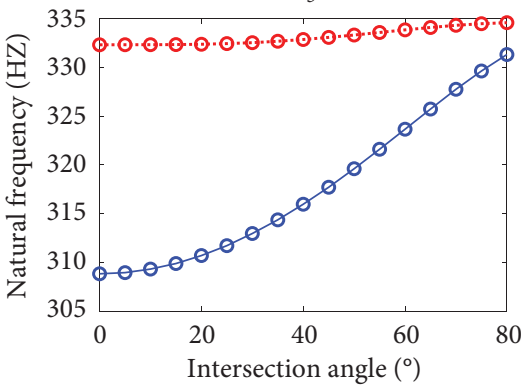

$\left(b_{6}\right)$

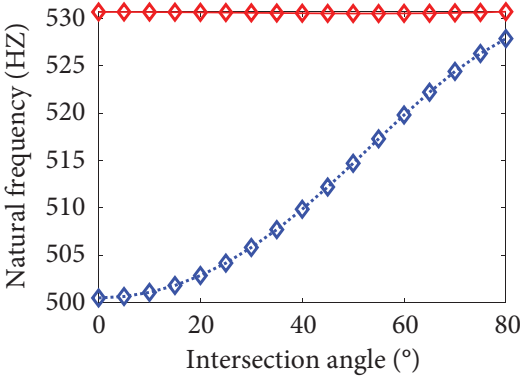

$\left(b_{9}\right)$

(b)

Figure 5: Continued. 


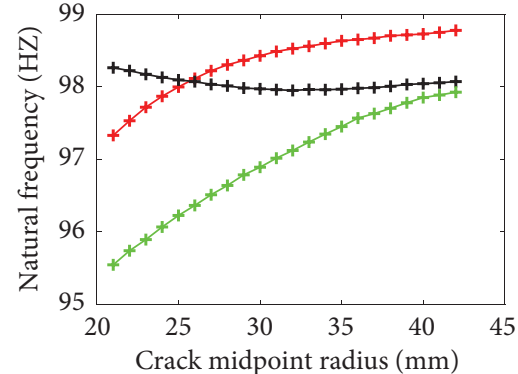

$\left(c_{1}\right)$

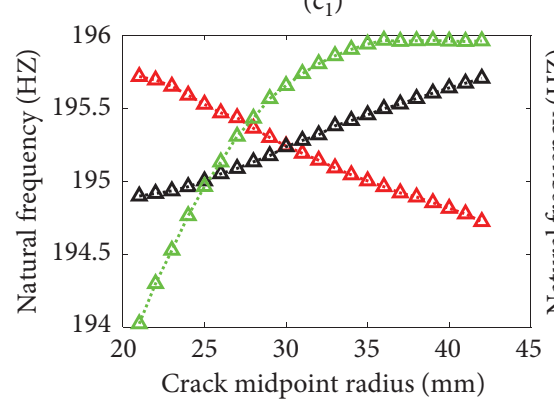

$\left(c_{4}\right)$

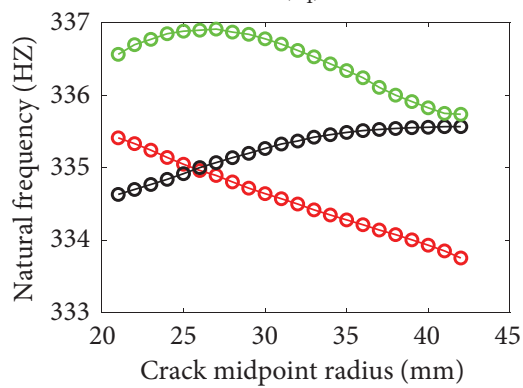

$\left(c_{7}\right)$

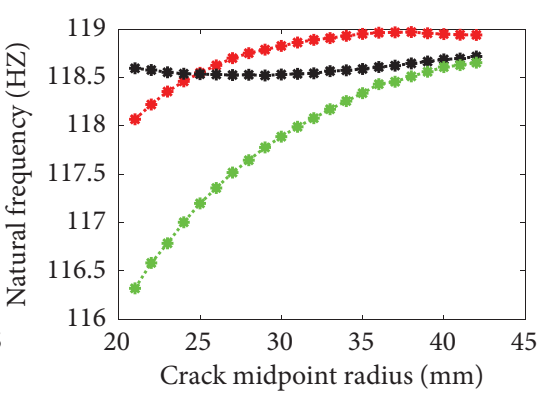

$\left(c_{2}\right)$

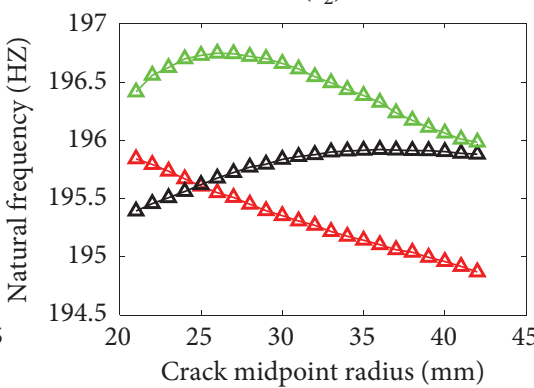

$\left(c_{5}\right)$

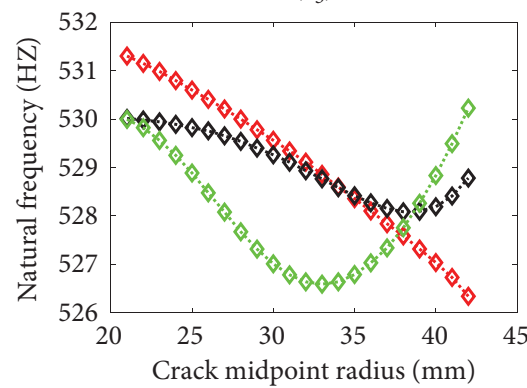

$\left(c_{8}\right)$

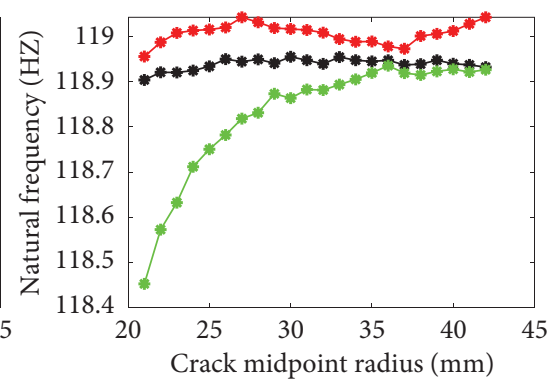

$\left(c_{3}\right)$

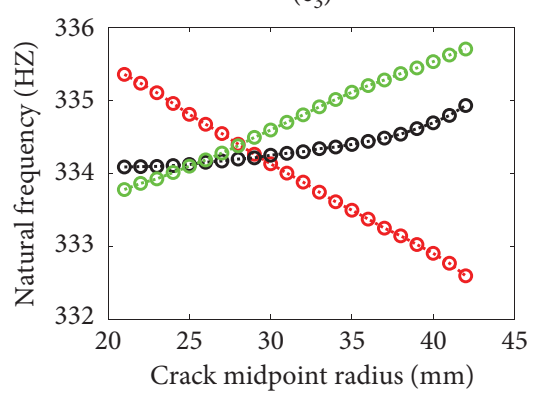

$\left(c_{6}\right)$

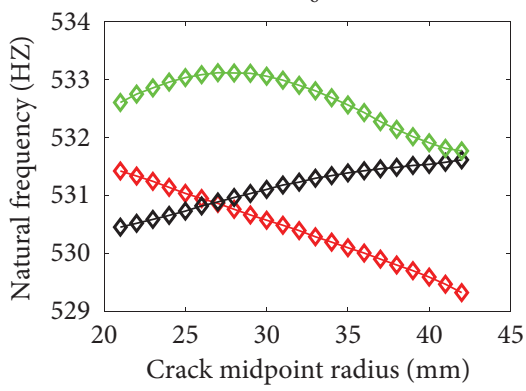

$\left(c_{9}\right)$

(c)

FIGURE 5: The natural frequencies curve of rotating flexible annular thin disks with four kinds of cracks of various parameters: $\left(\mathrm{a}_{i}\right)$ four kinds of cracked disks with isometric cracks, $\left(\mathrm{b}_{i}\right)$ two kinds of cracked disks with equal intersection angle, $\left(\mathrm{c}_{i}\right)$ three kinds of cracked disks with equal crack midpoint radius, $i$ is each vibration mode's order, and $i=1,2, \ldots, 9$. Blue: RO-crack, red: RC-crack, black: CF-crack, green: TGcrack. Solid line: mode A, dotted line: mode B. $+:(0,0), *:(0,1), \triangle:(0,2), \bigcirc:(0,3), \diamond:(0,4)$.

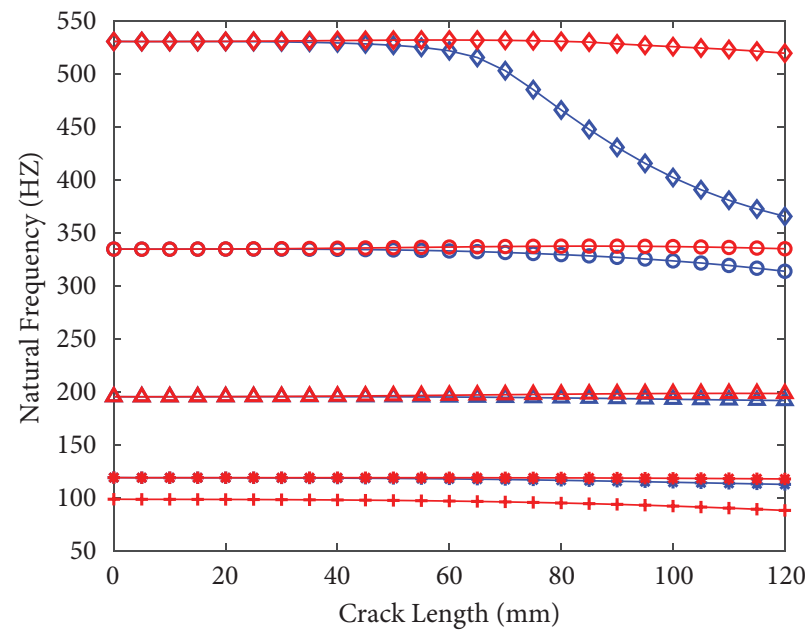

$\left(a_{1}\right)$

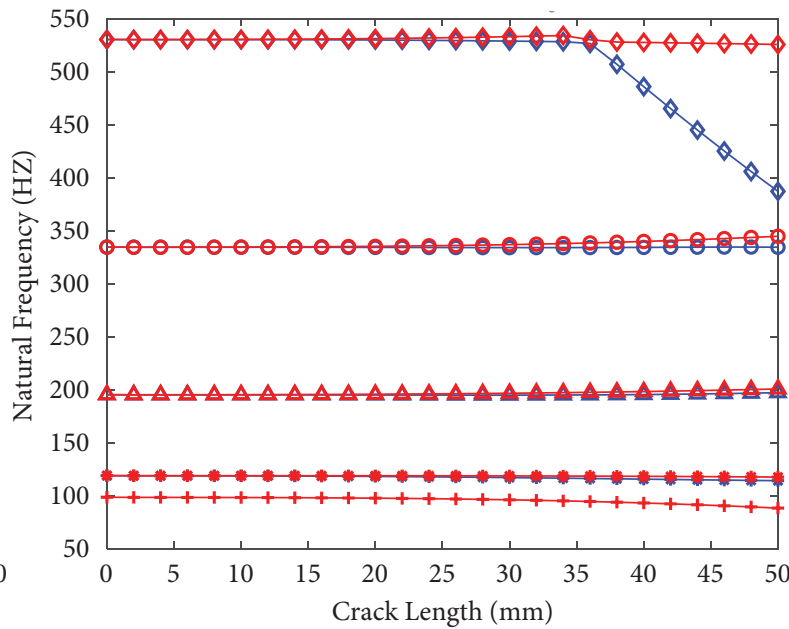

$\left(\mathrm{a}_{2}\right)$

(a)

Figure 6: Continued. 


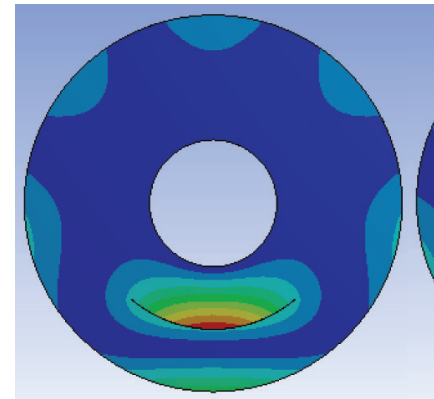

$\left(b_{1}\right)$

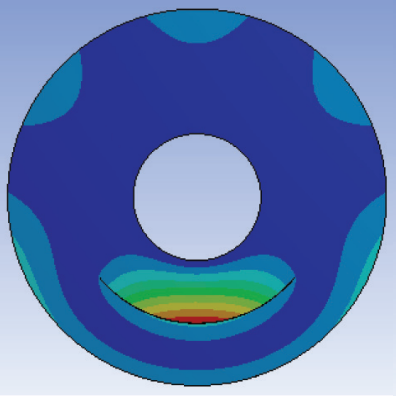

$\left(b_{2}\right)$

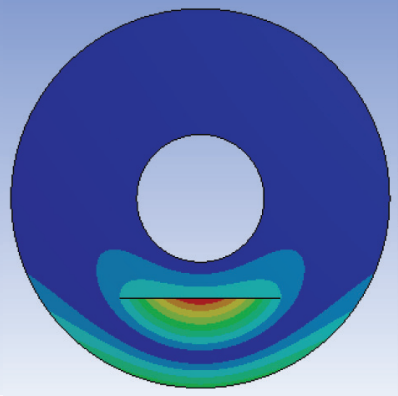

$\left(b_{3}\right)$

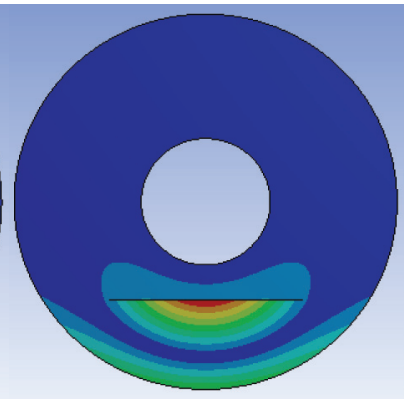

$\left(\mathrm{b}_{4}\right)$

(b)

Figure 6: The effect of vertical crack on the vibration characteristic of flexible cracked disk: $\left(\mathrm{a}_{i}\right)$ the natural frequency curve of the flexible annular thin disk with long cracks, and $i=1,2,\left(\mathrm{a}_{1}\right)$ CF-crack, $\left(\mathrm{a}_{2}\right)$ TG-crack. $\left(\mathrm{b}_{j}\right)$ The eighth modes of the flexible annular thin disks with long cracks, and $j=1,2,3,4,\left(\mathrm{~b}_{1}\right) \mathrm{CF}$-crack with a span angle of $80^{\circ}(\mathrm{CF} 80),\left(\mathrm{b}_{2}\right) \mathrm{CF}$-crack with a span angle of $100^{\circ}(\mathrm{CF} 100)$, (b $)_{3}$ TG-crack with a length of $40 \mathrm{~mm}$ (TG40), ( $\left.\mathrm{b}_{4}\right)$ TG-crack with a length of $48 \mathrm{~mm}$ (TG48).

TABLE 2: The natural frequency change ratios of the flexible cracked disk with intersection angle of $80^{\circ}$ relative to flawless disk.

\begin{tabular}{lccccccccc}
\hline Order & 1 & 2 & 3 & 4 & 5 & 6 & 7 & 8 & 9 \\
\hline RO16_A80 & 0.09 & -0.09 & 0.01 & -0.34 & -0.30 & -0.96 & -0.41 & -2.27 & -0.48 \\
RC16_A80 & -0.39 & -0.24 & -0.06 & 0.01 & 0.09 & 0.02 & 0.10 & -0.03 & 0.09 \\
\hline
\end{tabular}

\section{Experimental Verification}

4.1. Experimental Method. In order to verify the accuracy of theoretical research, the vibration performances of the highspeed rotating flexible disk with various cracks are studied by the experimental test under the dynamic measurement references by Gao et al. [26] and Che et al. [27]. During the experimental test, the flexible disk rotates stably at a high speed of 5000 RPM with a hard disk drive motor (provided by Seagate Technology Co.), the pulse excitation is applied by an electromagnet, and then the sound and displacement signal are collected by microphone KZ-501B (provided by China Shenzhen Kingze Technology Co., Ltd) and eddy displacement sensor DT3010-M/S2 (provided by MicroEpsilon (Beijing) Measurement Co., Ltd.), respectively. With the data acquisition card USB-4716 (provided by Advantech Technology (China) Co., Ltd.), the sampling frequency is $20 \mathrm{kHz}$ for signal collection, and each sampling time is 3 seconds. In addition, there is no filter used in the manuscript, since the sound and displacement signal are just used in frequency domain analysis only to obtain the disk vibration frequency at low frequency. The testing equipment for the rotating cracked disk is shown in Figure 7.

The sound and displacement signals are collected in the ground coordinate system while the natural frequency obtained by theoretical simulation is based on the rotating coordinate system. From Yang and Pei [28], when the ground coordinate system is taken as the reference, the natural frequency of vibration mode could split into positive travelling wave (PTW) and negative travelling wave (NTW). The relationship of natural frequency between the ground coordinate system and the rotating coordinate system can be expressed as

$$
\omega_{m, n}^{s}= \begin{cases}\left|\omega_{m, n}^{r}+n \Omega\right|, & \text { PTW } \\ \left|\omega_{m, n}^{r}-n \Omega\right|, & \text { NTW }\end{cases}
$$

where $\omega_{m, n}^{s}$ is the natural frequency of rotating flexible disk in the ground coordinate system; $\omega_{m, n}^{r}$ is the natural frequency of rotating flexible disk in the rotating coordinate system; $\Omega$ is the rotating speed of flexible disk; $m$ is the number of nodal circle; $n$ is the number of nodal diameters.

4.2. Data Processing. In order to facilitate quantitative analysis of the collected signals, the vibration modes and natural frequencies are separated from the collected signals by the time-frequency domain analysis. The voltage variation caused by displacement and sound intensity can be directly observed from time-domain signal. Meanwhile, the vibration characteristic information can be separated from frequency domain signals, such as the amplitude, energy, and frequency.

In order to ignore the interference signal existing in the environment and obtain the natural frequency of the flexible disk, it is necessary to preprocess the data. Firstly, the noise signal is filtered out from the experimental data by wavelet transform. Secondly, the mean value and trend term are eliminated by using the lower mode polynomial to perform the least square on the signal. Thirdly, the Fourier transform is performed on the data. And finally, the frequency domain graphs of displacement and sound signals are obtained. The time-domain analyses of processed data are shown in Figures 8 (a) and $8(\mathrm{~b})$, and the frequency domain analyses are shown in Figures 8(c) and 8(d).

It can be seen from Figures 8(a) and 8(b) that the displacement signal shows periodicity obviously, which is 


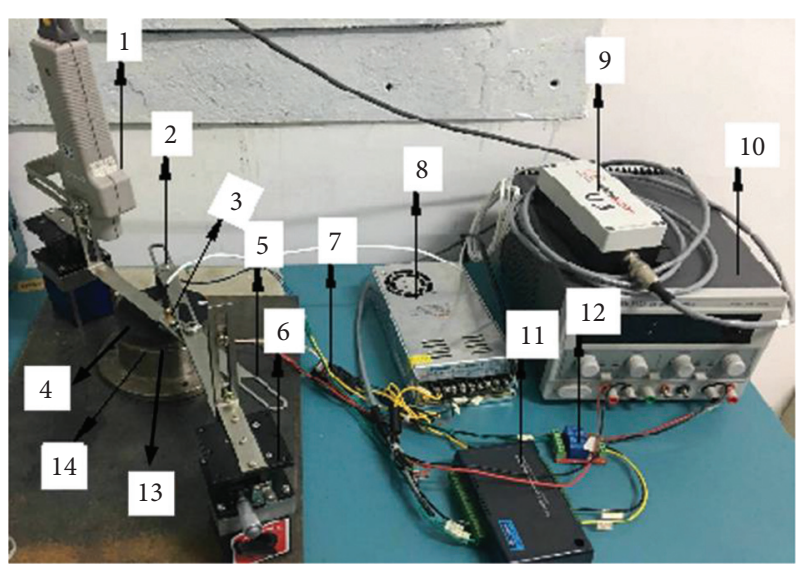

FIGURE 7: Vibration test equipment for rotating flexible cracked annular thin disk: 1, tachometer; 2, electromagnet; 3, displacement sensor; 4, motor assembly with flexible cracked disk; 5, bracket; 6 , magnetic base; 7, motor driver; 8, DC regulated power; 9 , displacement sensor controller; 10, adjustable DC power; 11, data acquisition board; 12, relay; 13, microphone; 14, motor base.

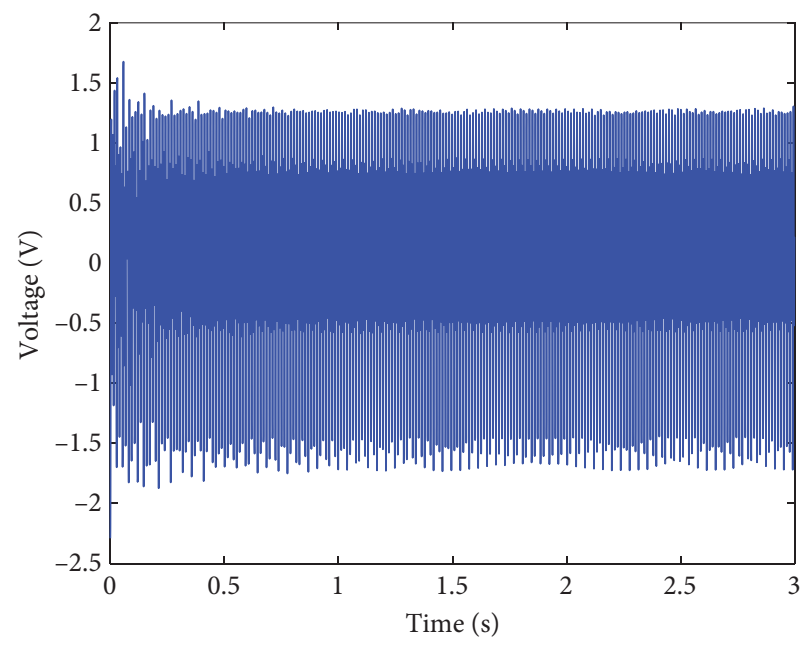

(a)

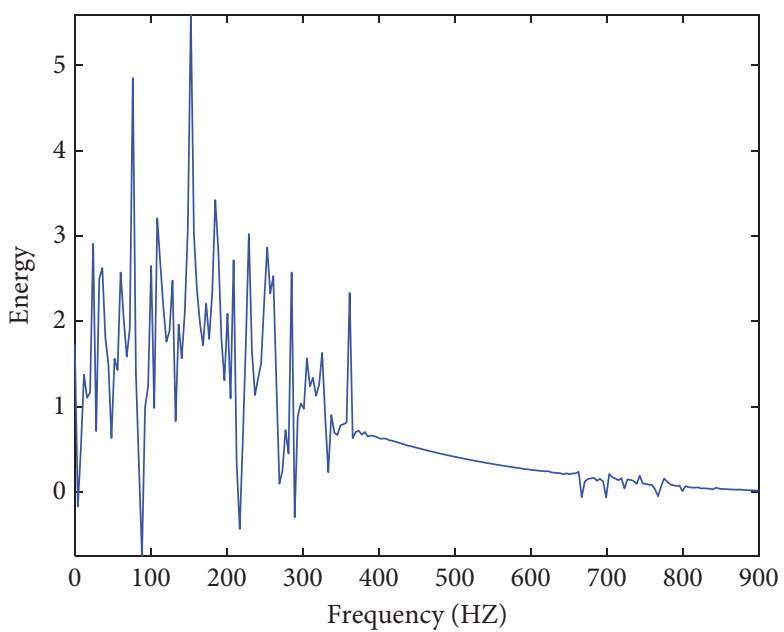

(c)

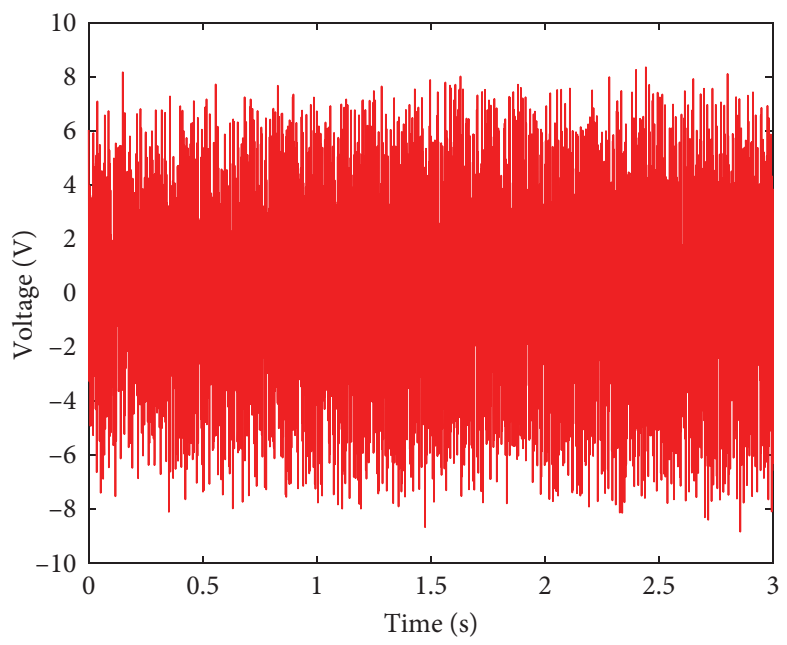

(b)

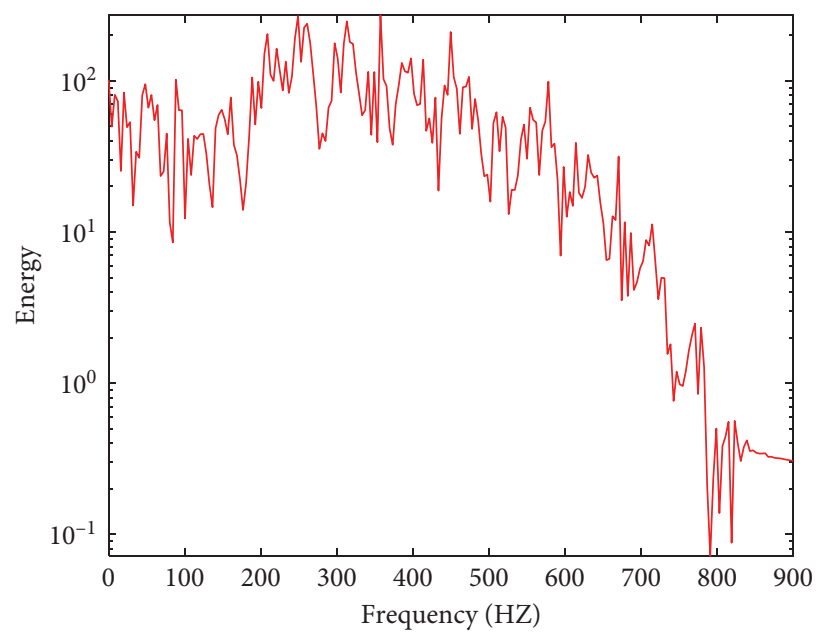

(d)

Figure 8: The time-frequency domain analysis of sound and deformation signals of flawless disk: (a) time-domain graph of displacement signal, (b) time-domain graph of sound signal, (c) frequency domain graph of displacement signal, and (d) frequency domain graph of sound signal. 


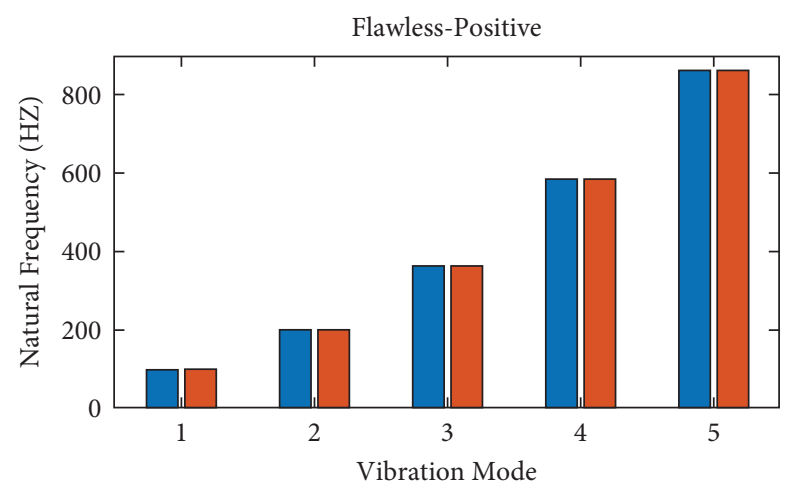

$\left(a_{1}\right)$

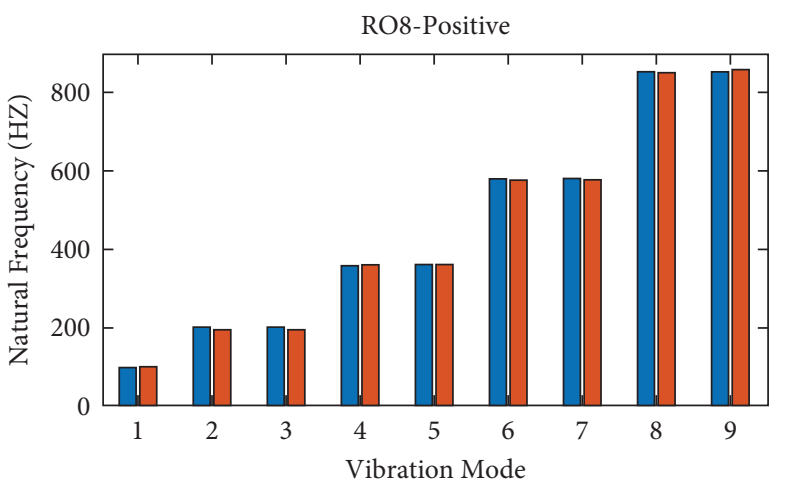

$\left(b_{1}\right)$

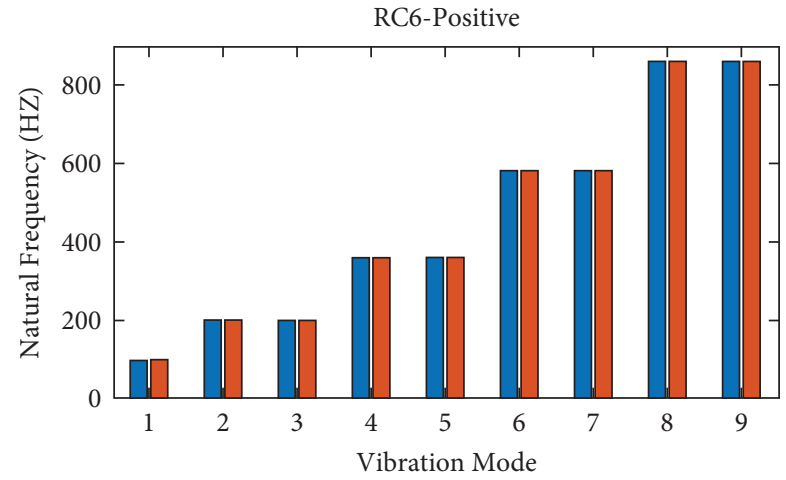

$\left(b_{3}\right)$

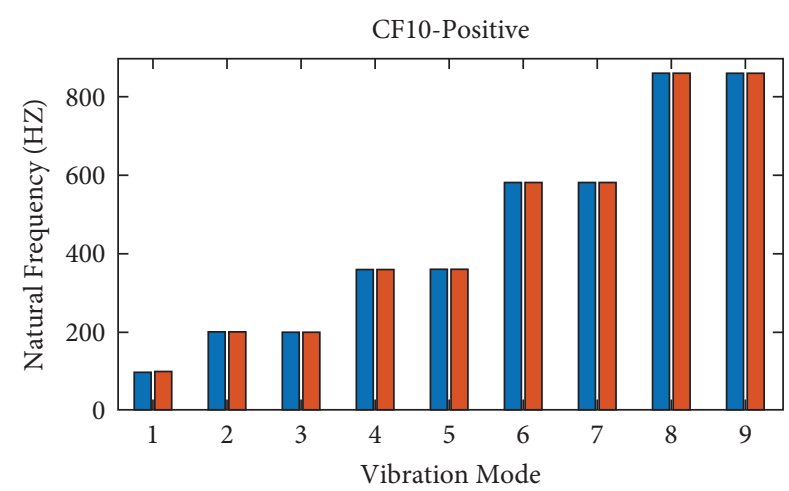

$\left(b_{5}\right)$

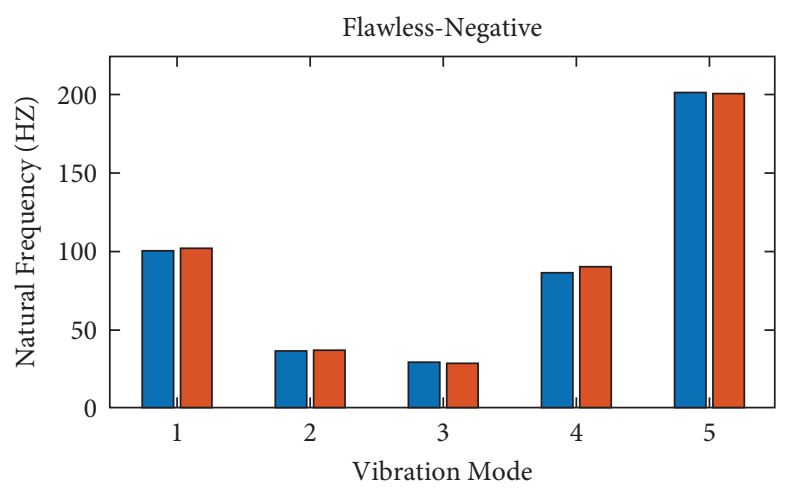

$\left(a_{2}\right)$

(a)

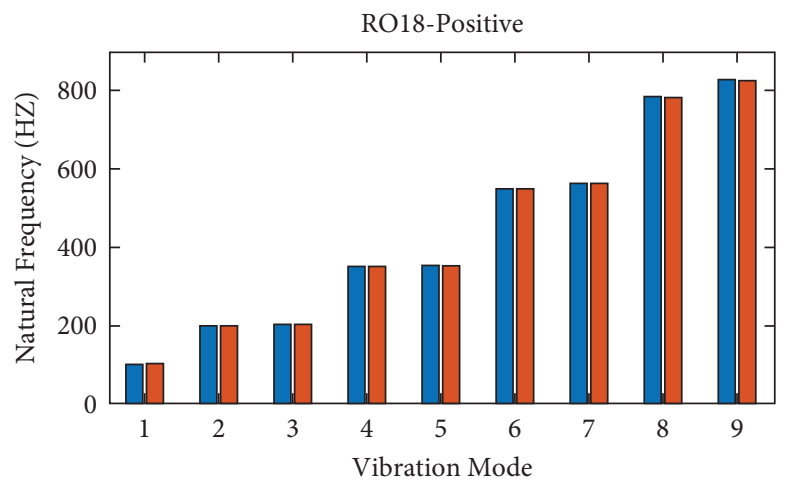

$\left(b_{2}\right)$

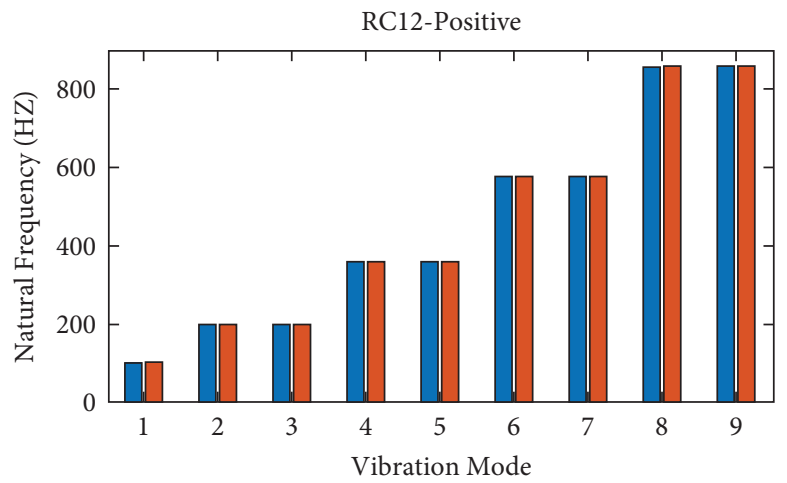

$\left(b_{4}\right)$

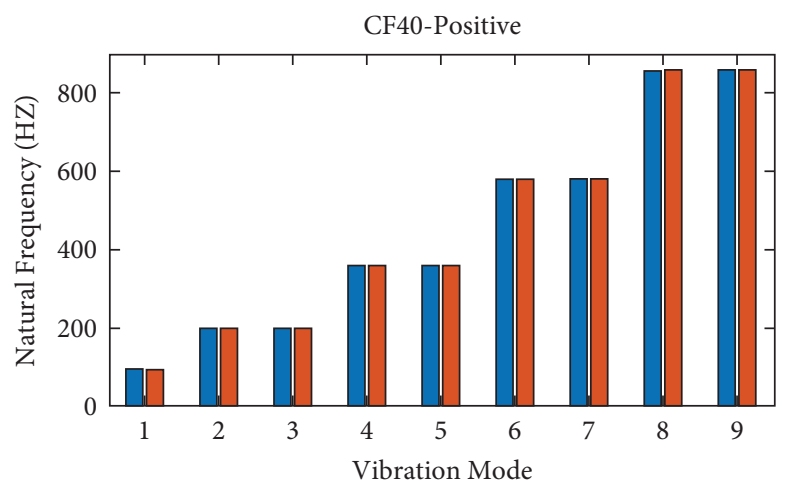

$\left(b_{6}\right)$

(b)

FIgURE 9: Continued. 

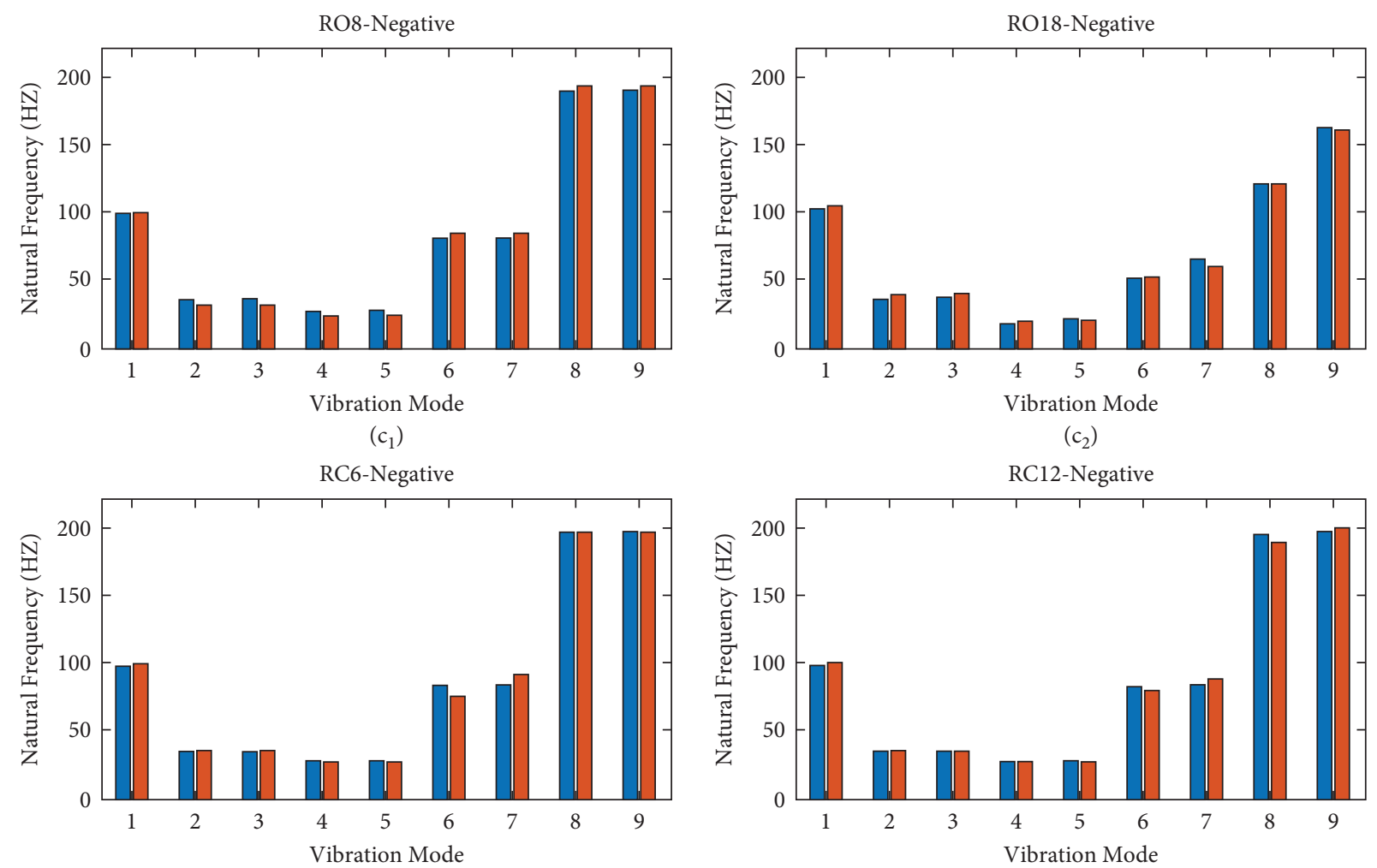

$\left(c_{3}\right)$

$\left(c_{4}\right)$
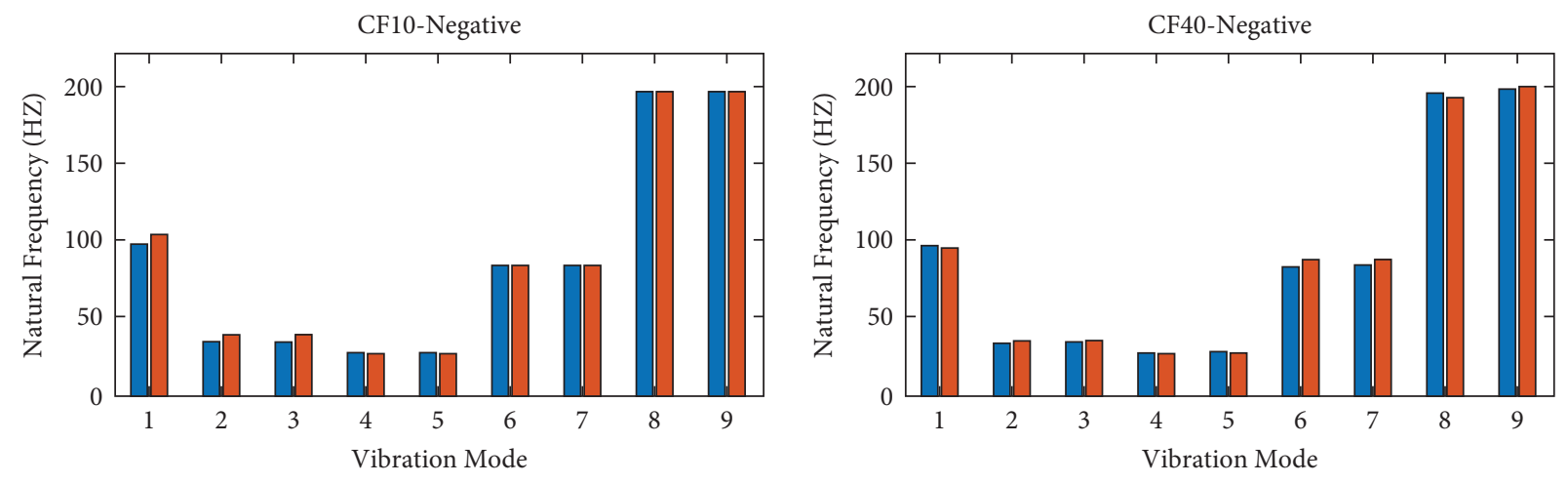

$\left(c_{5}\right)$

$\left(\mathrm{c}_{6}\right)$

(c)

FIGURE 9: The natural frequency of theoretical simulation and experimental test. $\left(a_{1}\right)$ Positive travelling wave of flawless disk, $\left(a_{2}\right)$ negative travelling wave of flawless disk, $\left(\mathrm{b}_{i}\right)$ positive travelling wave of flexible cracked disk, $\left(\mathrm{c}_{i}\right)$ negative travelling wave of flexible cracked disk, $i=1$, 2, .., 6. $\left(b_{1}\right)\left(c_{1}\right)$ RO8, $\left(b_{2}\right)\left(c_{2}\right)$ RO18, $\left(b_{3}\right)\left(c_{3}\right)$ RC6, $\left(b_{4}\right)\left(c_{4}\right)$ RC12, $\left(b_{5}\right)\left(c_{5}\right)$ CF10, $\left(b_{6}\right)\left(c_{6}\right)$ CF40. Blue bar: theoretical datum, red bar: experimental datum.

mainly composed of the regular periodic fluctuation and the weak random signals. The sound signal enhances significantly at the moment of applying the pulse but gradually slows down over time, which contains a major vibration signal and a variety of noise signals.

Frequency domain analysis uses frequency as the abscisic and amplitude as the ordinate. Each peak value in the frequency domain graph represents a vibration mode and its corresponding abscissa represents its natural frequency. According to equation (1), the natural frequencies of positive and negative waves can be obtained by decomposing theoretical simulation results. The natural frequency of theoretical simulation and experimental test of different cracked disks are shown in Figure 9. The horizontal coordinate represents each mode, and the ordinate represents the natural frequency. 
4.3. Data Analysis. It can be seen from Figure 9 that the errors between experimental results and theoretical datum are tiny except for the negative wave of the lower modes; the error of lower mode could be accepted due to its small value. Based on the high matching of simulation and experiment, the method of theoretical simulation is credible. The experimental result in Figure $9\left(c_{i}\right)$ shows that the effect of RO-crack is obvious on the natural frequency especially the negative travelling waves. As a whole, the natural frequency decreases with cracks extending, the effect regular is higher mode > lower mode, negative wave $>$ positive wave, and the intensity of effect is radial crack $>$ CF-crack, opening crack $>$ closed crack. The change rule of the theoretical simulation is verified by the experimental test.

\section{Conclusion}

In this paper, the vibration characteristics of high-speed rotating flexible annular thin disks with various cracks are studied by theoretical simulation and experimental test; the following conclusions are obtained:

(1) The effect regular of cracks on natural frequency of the rotating flexible annular thin disks is radial cracks $>$ vertical cracks, opening cracks $>$ closed cracks.

(2) The bigger the nodal diameter is, the more obvious the effect gets. The natural frequencies have a greater change when a nodal diameter of vibration modes is just located on the crack.

(3) Radial cracks, especially RO-cracks, can significantly reduce the natural frequencies of the rotating flexible disks, which make the disk more prone to resonance, even causing production accidents.

(4) Based on the crack detection method, if the natural frequency of lower modes decreases significantly, the disk may contain RO-cracks. However, the other cracks cannot be excluded by the lower mode, and the higher modes should be further detected. If the natural frequency of higher mode decreases obviously, the flexible disk may include CF-cracks, TGcracks, or RC-cracks. On the contrary, the flexible annular thin disk is complete with no cracks.

(5) Based upon above investigations on the mode shape and natural frequency of rotating flexible cracked annular thin disk, some specialized researches as the future work should be carried out to predict, identify, and diagnose the fault of rotating disk system in a smart and online way.

\section{Nomenclature}

$\begin{array}{ll}d: & \text { Crack maximum width } \\ E: & \text { Elasticity modulus } \\ h: & \text { Disk thickness } \\ l_{C F}: & \text { Circumferential crack arc length } \\ l_{R O}: & \text { Radial opening crack length }\end{array}$

$l_{R C}: \quad$ Radial closed crack length

$l_{T G}:$ Tangential crack length

$m$ : Numbers of nodal circle

$n$ : $\quad$ Numbers of nodal diameter

$R_{C F}:$ Crack midpoint radius of circumferential crack

$R_{i}$ : $\quad$ Disk inner radius

$R_{o}$ : Disk outer radius

$R_{R C}$ : Crack midpoint radius of radial closed crack

$R_{T G}$ : Crack midpoint radius of tangential crack

$t$ : Signal acquisition time

$v$ : Poisson's ratio

$\theta: \quad$ Circumferential crack span angle

$\rho$ : Density

$\omega_{m, n}^{s}:$ Natural frequency in the ground coordinate system

$\omega^{r}$ : Natural frequency in the rotating coordinate system

$\Omega:{ }^{m, n} \quad$ Disk rotating speed.

\section{Data Availability}

For the finite element analysis data by ANSYS and the experimental original and analysis data by MATLAB underlying the findings of this paper, the authors declare that all these data can be allowed for readers and researchers to verify the results of this paper replicate the analysis and conduct secondary analyses.

\section{Conflicts of Interest}

The authors declare that they have no conflicts of interest.

\section{References}

[1] H. Lamb and R. V. Southwell, "The vibrations of a spinning disk," Proceedings of the Royal Society of London - Series A: Containing Papers of a Mathematical and Physical Character, vol. 99, no. 699, pp. 272-280, 1921.

[2] J. Chung, J.-E. Oh, and H. H. Yoo, "Non-linear vibration of a flexible spinning disc with angular acceleration," Journal of Sound and Vibration, vol. 231, no. 2, pp. 375-391, 2000.

[3] M. K. Kwak and M. Amabili, "Hydroelastic vibration of freeedge annular plates," Journal of Vibration and Acoustics, vol. 121, no. 1, pp. 26-32, 1999.

[4] M. Amabili and G. Dalpiaz, "Vibrations of base plates in annular cylindrical tanks: theory and experiments," Journal of Sound and Vibration, vol. 210, no. 3, pp. 329-350, 1998.

[5] M. Amabili and R. Garziera, "Comments and additions to "Transverse vibrations of circular, annular plates with several combinations of boundary conditions", Journal of Sound and Vibration, vol. 228, no. 2, pp. 443-446, 1999.

[6] M. Krawczuk, A. Żak, and W. Ostachowicz, "Finite element model of plate with elasto-plastic through crack," Computers \& Structures, vol. 79, no. 5, pp. 519-532, 2001.

[7] M. Krawczuk, "Natural vibrations of rectangular plates with a through crack," Archive of Applied Mechanics, vol. 63, pp. 491-504, 1993.

[8] R. Ismail and M. P. Cartmell, "An investigation into the vibration analysis of a plate with a surface crack of variable angular orientation," Journal of Sound and Vibration, vol. 331, no. 12, pp. 2929-2948, 2012.

[9] R. M. Lin and T. Y. Ng, "Applications of higher-order frequency response functions to the detection and damage 
assessment of general structural systems with breathing cracks," International Journal of Mechanical Sciences, vol. 148, pp. 652-666, 2018.

[10] E. P. Carden and P. Fanning, "Vibration based condition monitoring: a review," Structural Health Monitoring, vol. 3, no. 4, pp. 355-377, 2004.

[11] P. Pennacchi, N. Bachschmid, and A. Vania, "A model-based identification method of transverse cracks in rotating shafts suitable for industrial machines," Mechanical Systems and Signal Processing, vol. 20, no. 8, pp. 2112-2147, 2006.

[12] S. Bennoud, M. Zergoug, and A. Allali, "Numerical simulation for cracks detection using the finite elements method," The International Journal of Multiphysics, vol. 8, no. 1, pp. 1-10, 2014.

[13] X. Chen, "Nonlinear responses analysis caused by slant crack in a rotor-bearing system," Journal of Vibroengineering, vol. 18, no. 7, pp. 4369-4387, 2016.

[14] A. A. Cavalini Jr, L. Sanches, N. Bachschmid, and V. Steffen Jr, "Crack identification for rotating machines based on a nonlinear approach," Mechanical Systems and Signal Processing, vol. 79, pp. 72-85, 2016.

[15] N. K. Anifantis, R. L. Actis, and A. D. Dimarogonas, "Vibration of cracked annular plates," Engineering Fracture Mechanics, vol. 49, no. 3, pp. 371-379, 1994.

[16] J. Chung and W. Kim, "Fracture identification and prevention of a high-speed optical disk with a crack," IEEE Transactions on Consumer Electronics, vol. 48, no. 2, pp. 248-253, 2002.

[17] V. Mirsalimov and N. Kalantarly, "Interaction of bridged cracks in a circular disk with mixed boundary conditions," Mechanika, vol. 21, pp. 361-366, 2015.

[18] R. Pramod, M. E. Shashi Kumar, and S. Mohan Kumar, "Modal analysis of annular plate with crack and its effect on natural frequency," Applied Mechanics and Materials, vol. 813-814, pp. 910-914, 2015.

[19] E. Derakhshan, M. Fakhrzarei, and S. Derakhshan, "Analytical solution for free vibration of annular Mindlin plate with a circumferential open crack," The Volume 24, No 3, September 2019, The International Journal of Acoustics and Vibration, vol. 24, no. 3, pp. 494-503, 2019.

[20] H. Bahaloo, J. Papadopolus, R. Ghosh, E. Mahdi, A. Vaziri, and H. Nayeb-Hashemi, "Transverse vibration and stability of a functionally graded rotating annular disk with a circumferential crack," International Journal of Mechanical Sciences, vol. 113, pp. 26-35, 2016.

[21] T. Bose and A. R. Mohanty, "Large amplitude axisymmetric vibration of a circular plate having a circumferential crack," International Journal of Mechanical Sciences, vol. 124-125, pp. 194-202, 2017.

[22] J. Yuan, P. G. Young, and S. M. Dickinson, "Natural frequencies of circular and annular plates with radial or circumferential cracks," Computers \& Structures, vol. 53, no. 2, pp. 327-334, 1994.

[23] J. Yuan and S. M. Dickinson, "On the vibration of annular, circular and sectorial plates with cut-outs or on partial supports," Computers \& Structures, vol. 58, no. 6, pp. 1261-1264, 1996.

[24] A. Demir and V. Mermertaş, "A study on annular plates with radial through cracks by means of sector type element," Journal of Sound and Vibration, vol. 300, no. 3-5, pp. 466-478, 2007.

[25] A. Demir and V. Mermertaş, "Natural frequencies of annular plates with circumferential cracks by means of sector element," Engineering Fracture Mechanics, vol. 75, no. 5, pp. 1143-1155, 2008.
[26] Y. Gao, Z. Rao, J. Yin, G. Tian, and R. Li, "Measurement of multi-component hydraulic loads with compensation of dynamic load," IEEE Sensors Journal, vol. 21, pp. 231-238, 2020.

[27] X. Che, Y. Gao, and H. Xu, "Simulation design and realization of axial force measurement sensor of pump,"vol. 2, pp. 959962, in Proceedings of The 9th International Conference on Electronic Measurement \& Instruments, vol. 2, IEEE, Beijing, China, 2009.

[28] F. Yang and Y. Pei, "Coupling parametric instability and resonance of a rotating flexible disk with unstressed initial runout under several parametrical excitations," in Proceedings of the Institution of Mechanical Engineers - Part C: Journal of Mechanical Engineering ScienceSAGE Publications Ltd, Thousand Oaks, California, United States, 2021. 